\title{
Use of ultramicroindentation to evaluate the degradation of sputtered coatings
}

\author{
A. Cavaleiro ${ }^{\mathrm{a}, *}$, C. Louro ${ }^{\mathrm{a}}$, J. V. Fernandes ${ }^{\mathrm{a}}$, C. M. A. Brett ${ }^{\mathrm{b}}$ \\ ${ }^{a}$ Departamento de Engenharia Mecânica \\ ${ }^{\mathrm{b}}$ Departamento de Quimica, Universidade de Coimbra, Polo II, Pinhal de Marrocos, 3030 Coimbra, Portugal
}

\begin{abstract}
The aim of this research work was to study the influence of chemical degradation on the mechanical properties of the non-degraded zones of sputtered $\mathrm{W}-\mathrm{N}-\mathrm{Ti}$ coatings. For this, an ultramicroindentation technique has been used before and after degradation, either on the zones between the pits in the corroded samples, or on the non-oxidised layers after removal of the top degraded layers. By using different applied loads it was possible to obtain results with and without the influence of the substrate. Thus, two types of results were obtained, those determined by using an empirical model, which eliminates the influence of the substrate, and those measured directly.

Very small differences of less than $20 \%$ were obtained in the measured values before and after degradation, indicating that the non-degraded zones maintain their as-deposited mechanical properties. (C) 1998 Elsevier Science Ltd. All rights reserved.
\end{abstract}

\section{Introduction}

During degradation of a material in a chemically aggressive environment, different mechanisms can be active in such a way that two principal types of degradation can be considered :

- uniform degradation over all the surface of the sample with the formation of degraded material layers of constant thickness;

-non-uniform degradation of the sample with zones presenting a variable state of destruction adjacent to zones where the degradation is not observable.

If the degradation process is being analysed on a coated sample, on which the coating was applied in order to mechanically protect the base material, it is of crucial importance to evaluate the mechanical characteristics of the remaining non-degraded coating material, in order to estimate whether its usefulness for the functions for which it was designed is impaired. In fact, the partial destruction of the coating can, in some situations, determine the total failure of the component, whereas in other cases, the presence of some non-degraded material is the determinant parameter.

Its high depth resolution makes ultramicroindentation

\footnotetext{
* Corresponding author.
}

a powerful technique for the evaluation of the hardness $(H)$ and the Young's modulus $(E)$ of materials in the form of thin films [1-5]. Either by using very low indentation loads or by using appropriate models which separate conveniently the contribution of the substrate and film it is possible to access the $E$ and $H$ values of the coatings at some predefined zones of their surface [6].

In previous studies a detailed oxidation and corrosion characterisation was carried out on $\mathrm{W}$-based sputtered coatings of the system $\mathrm{W}-\mathrm{N} / \mathrm{C}-\mathrm{M}(\mathrm{M}=\mathrm{Ti}, \mathrm{Ni}, \mathrm{Al})$ [711]. Generically it was observed that oxidation gave rise to uniform coating degradation over all the sample surface, whereas the corrosion took place only in localised zones of the sample by pitting. The aim of this research study was to investigate if the degradation can alter the mechanical characteristics of the material in the non-degraded zones, by using the ultramicroindentation technique. Four samples coated by sputtering with films of the system $\mathrm{W}-\mathrm{N}-\mathrm{Ti}$ were selected for this study, two that were previously oxidised at $600^{\circ} \mathrm{C}$ over $30 \mathrm{~min}$ and two corroded in an aqueous $0.1 \mathrm{M}$ potassium chloride solution over $4 \mathrm{~h}$.

\section{Experimental details}

All the coatings were sputter coated in a Hartec d.c. magnetron sputtering apparatus; deposition was carried 
out at a power density of $11 \mathrm{~W} \mathrm{~cm}^{-2}$ and a negative substrate bias at $70 \mathrm{~V}$. The total gas pressure employed during the deposition was $0.3 \mathrm{~Pa}$; the samples containing $\mathrm{N}$ were deposited in a mixture of argon and nitrogen, with a partial pressure ratio $P_{\mathrm{N} 2} / P_{\mathrm{Ar}}=\frac{1}{2}$, the deposition rate was typically $6 \mu \mathrm{m} \mathrm{h}^{-1}$.

The oxidation process was carried out in a Polymer Science Thermobalance at a temperature of $600^{\circ} \mathrm{C}$ with an isothermal time of $30 \mathrm{~min}$. Industrial air of $99.995 \%$ purity with a flow rate of $55 \mathrm{ml} \mathrm{min}{ }^{-1}$ was introduced in the furnace during oxidation tests.

All electrochemical experiments to characterise the corrosion behaviour of the coated samples were carried out using a solution of $0.1 \mathrm{M}$ potassium chloride prepared from analytical grade reagent and ultrapure water (Millipore Milli-Q, resistivity $>18 \mathrm{M} \Omega \mathrm{cm}$ ). Solutions were not deaerated. Corrosion potential measurements, voltammetric experiments and impedance measurements in combination with scanning electron and optical microscope observations were used to characterise the coatings.

The hardness and the Young's modulus were measured by the depth-sensing indentation technique using a Fischerscope H100. The load $P$ was increased in steps $(60$ steps) until the nominal load $(100,200$ and $400 \mathrm{mN}$ ) was reached, the same steps being used during unloading. At each step, the indentation depth $h$ was measured and stored on the computer in the form of $h$ vs $P$. The hardness was calculated as the ratio of the applied load to the projected area of contact between the indenter and the sample. By knowing the indenter geometry (Vickers) the projected area can be evaluated from the plastic depth $h_{\mathrm{p}}$, which was obtained by fitting a straight line tangent to the unloading curve at the point of maximum load and then extrapolating to zero $[1,2]$. Due to geometrical imperfections of the indenter and indentations, the $h_{\mathrm{p}}$ values were corrected by the method proposed in another paper [4], through the equation:

$h_{\mathrm{pc}}=0.052+1.095 h_{\mathrm{p}}$

where $h_{\mathrm{pc}}$ is the corrected value.

The Young's modulus was calculated using the formula :

$$
E=\frac{\left(1-v^{2}\right) \sqrt{\frac{\pi}{24.5}}}{2 h_{\mathrm{pc}}\left(\frac{\mathrm{d} h}{\mathrm{~d} P}\right)-\frac{\left(1-v_{\mathrm{o}}^{2}\right)}{E_{\mathrm{o}}} \sqrt{\frac{\pi}{24.5}}}
$$

where $\mathrm{d} h / \mathrm{d} P$ is the compliance and $E_{\mathrm{o}}$ and $v_{\mathrm{o}}$ are the Young's modulus and Poissons's ratio, respectively, for the indenter (for diamond $E_{\mathrm{o}}=1050 \mathrm{GPa}$ and $v_{\mathrm{o}}=0.07$ ).

Each hardness and Young's modulus value is a result of at least five indentation tests. In the case of corroded samples, after a careful cleaning of the sample surface, the indentations were made in the centre of the zones that separate the corrosion pits. Indenting zones where corrosion products were deposited were avoided. For oxidised samples the preparation procedure for sample indentation is much more dificult to perform owing to the necessity of detaching the oxide layers from the remaining non-degraded coating. For that purpose, careful successive polishing with fine diamond paste $(1 \mu \mathrm{m})$ was carried out followed by optical microscopy observations in order to assess total elimination of the oxide layers.

\section{Results and discussion}

\subsection{As-deposited samples}

Table 1 summarises the main characteristics of the coatings after deposition and before test degradation. The smaller thickness of the coatings used for the oxidation measurements and also the lower substrate hardness for these samples should be noted. Moreover, it should be emphasised that above $600^{\circ} \mathrm{C}$ oxidation temperature no variation in the substrate hardness was detected.

\subsection{Samples after corrosion}

Table 2 summarises the main characteristics of the coatings after corrosion tests. Figure 1 shows coating degradation by pitting. It was found that the presence

Table 1

Description of as-deposited sputtered $\mathrm{W}-\mathrm{Ti}$ and $\mathrm{W}-\mathrm{N}-\mathrm{Ti}$ films

\begin{tabular}{|c|c|c|c|c|c|c|}
\hline Target & Substrate & $\begin{array}{l}\text { Substrate } \\
\text { hardness }(\mathrm{GPa})\end{array}$ & Coating & $\begin{array}{l}\text { Thickness } \\
(\mu \mathrm{m})\end{array}$ & Structure & $\begin{array}{l}\text { Degradation } \\
\text { process }\end{array}$ \\
\hline $\mathrm{W}+10$ wt. $\% \mathrm{Ti}$ & Carbon steel & 5.1 & $\mathrm{~W}_{93} \mathrm{Ti}_{7}$ & 3.9 & $\alpha-W$ & Oxidation \\
\hline $\mathrm{W}+10$ wt. $\% \mathrm{Ti}$ & Carbon steel & 5.1 & $\mathrm{~W}_{43} \mathrm{Ti}_{13} \mathrm{~N}_{44}$ & 3.2 & $\mathrm{~W}_{2} \mathrm{~N} / \mathrm{TiN}$ & Oxidation \\
\hline $\mathrm{W}+10$ wt. $\% \mathrm{Ti}$ & M2(AISI) & 8.6 & $\mathrm{~W}_{42} \mathrm{Ti}_{11} \mathrm{~N}_{47}$ & 4.0 & $\mathrm{~W}_{2} \mathrm{~N} / \mathrm{TiN}$ & Corrosion \\
\hline $\mathrm{W}+20$ wt. $\% \mathrm{Ti}$ & M2(AISI) & 8.6 & $\mathrm{~W}_{72} \mathrm{Ti}_{28}$ & 4.2 & $\alpha-W$ & Corrosion \\
\hline
\end{tabular}


Table 2

Characteristics of coatings after corrosion in $0.1 \mathrm{M} \mathrm{KCl}$

\begin{tabular}{clcc}
\hline & & $\mathrm{W}_{72} \mathrm{Ti}_{28}$ & $\mathrm{~W}_{42} \mathrm{Ti}_{11} \mathrm{~N}_{47}$ \\
\hline Open circuit $(t=4 \mathrm{~h})$ & $E_{\text {cor }}(\mathrm{V})$ & -0.48 & -0.46 \\
*Tafel plots $(t=4 \mathrm{~h})$ & $E_{\text {cor }}(\mathrm{V})$ & -0.60 & -0.52 \\
& $\left.I_{\text {cor }}(\mu \mathrm{A} \mathrm{cm})^{-2}\right)$ & 11.6 & 14.8 \\
Linear polarisation & $R_{\mathrm{p}}\left(\mathrm{k} \Omega \mathrm{cm}^{2}\right)$ & 1.99 & 2.17 \\
resistance $(t=10 \mathrm{~min})$ & & & \\
Impedance $(t=10 \mathrm{~min})$ & $R_{\mathrm{ct}}\left(\mathrm{k} \Omega \mathrm{cm}^{2}\right)$ & 1.5 & 2.2 \\
$(t=1 \mathrm{~h})$ & $R_{\mathrm{ct}}\left(\mathrm{k} \Omega \mathrm{cm}^{2}\right)$ & 0.5 & 1.8
\end{tabular}

* Scans performed every h from -0.8 to $-0.3 \mathrm{~V}$ vs SCE.

( $E_{\text {cor }}$ - corrosion potential vs SCE; $I_{\text {cor }}$ - corrosion current ; $R_{\mathrm{p}}$-linear polarisation resistance; $R_{\mathrm{cf}}$-change transfer resistance; $t$-time after immersion in electrolyte).

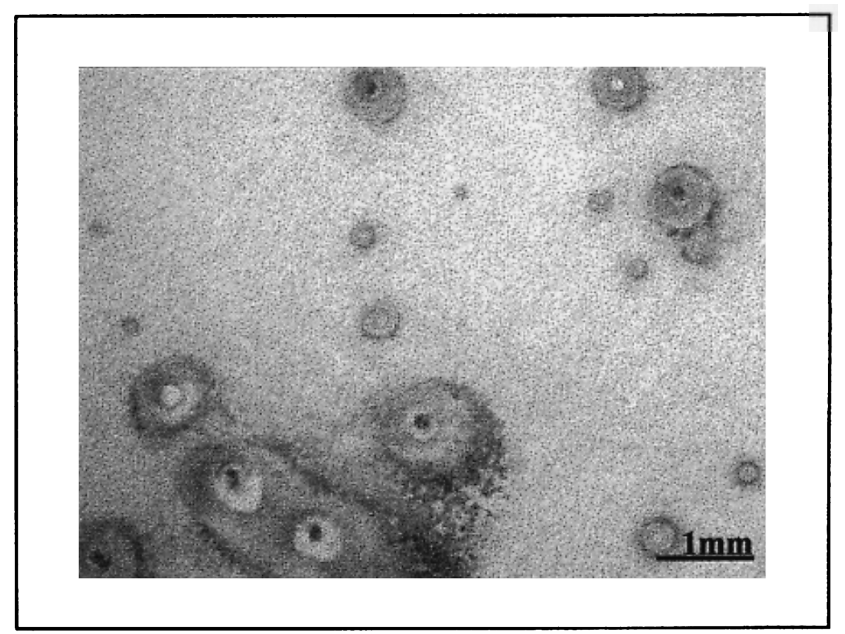

a)

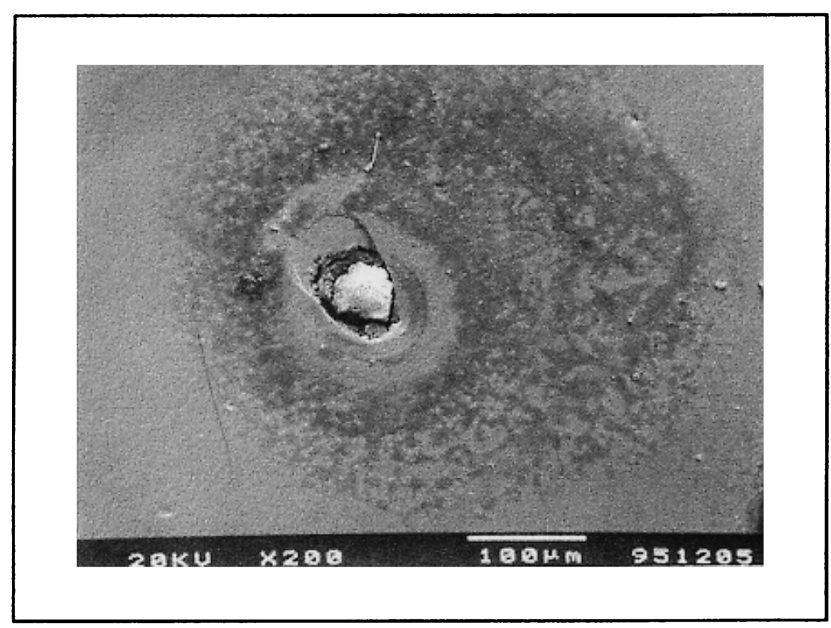

b)

Fig. 1. Micrographs of $\mathrm{W}_{27} \mathrm{Ti}_{28}$ film corroded in $0.1 \mathrm{M} \mathrm{KCl}$ solution: a) General view obtained in optical microscope ; b) Detail of a corrosion pit observed by SEM. of nitrogen in the films is beneficial in reducing pitting corrosion, although the mechanisms of pitting appear to be the same [9-11].

\subsection{Samples after oxidation}

Table 3 presents the main characteristics of the coatings after oxidation tests. As can be observed in Fig. 2a and $b$, the degradation is uniform over all the coating

Table 3

Characteristics of coatings after oxidation at $600^{\circ} \mathrm{C}$

\begin{tabular}{llll}
\hline Coating & $\begin{array}{l}\text { Weight gain } \\
\left(\mathrm{mgcm}^{-2}\right)\end{array}$ & $\begin{array}{l}\text { Oxide thickness } \\
(\mu \mathrm{m})\end{array}$ & $\begin{array}{l}\text { Oxide } \\
\text { phases }\end{array}$ \\
\hline $\mathrm{W}_{93} \mathrm{Ti}_{7}$ & 0.0658 & 0.7 & $\mathrm{TiO}_{2}+\mathrm{WO}_{x}$ \\
$\mathrm{~W}_{43} \mathrm{Ti}_{13} \mathrm{~N}_{44}$ & 0.0578 & 0.5 & $\mathrm{WO}_{x}$ \\
\hline
\end{tabular}

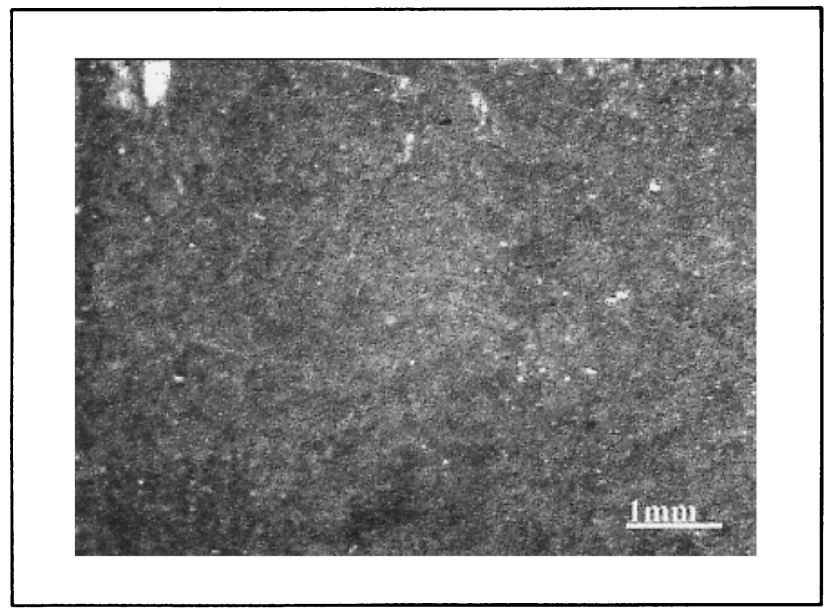

a)

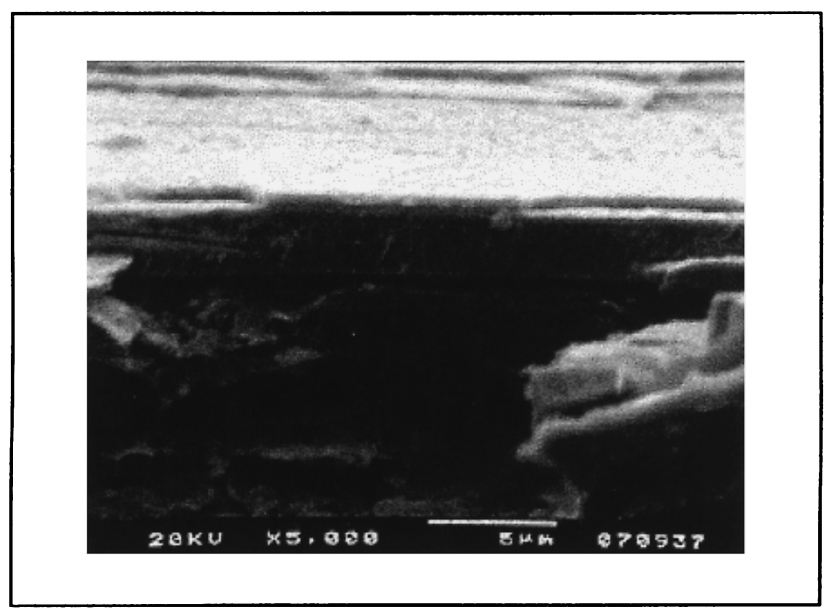

b)

Fig. 2. Micrographs of $\mathrm{W}_{43} \mathrm{Ti}_{13} \mathrm{~N}_{44}$ film oxidised in air at $600^{\circ} \mathrm{C}$ : a) General view obtained in optical microscope; b) Detail of the cross section of the sample observed by SEM. 
surface. The oxidation resistance is better for the film containing nitrogen although for higher annealing temperatures the inverse had been observed in other work [7, $8]$.

\subsection{Ultramicroindentation results}

The ultramicroindentation tests were carried out on as-deposited and corroded samples with nominal applied loads of 200 and $400 \mathrm{mN}$. In the case of $200 \mathrm{mN}$ load no influence of the substrate on the measured hardness was observed (see Fig. 3 as an example of a typical indentation load vs indentation depth curve). However, if the procedure recently proposed by Fernandes et al to analyse the loading part of the curve is used, the influence of the substrate is easily detected for the $400 \mathrm{mN}$ load [6]. In fact, the influence of the substrate should be apparent when the linearity of the $\log P$ vs $\log h$ curve, during loading is changed (compare the 200 and the $400 \mathrm{mN}$ loading curves in the example shown in Fig. 4). This change corresponds to a critical indentation depth $h_{\mathrm{c}}$ from which it is possible to separate the hardness of the film from that of the substrate using the empirical model

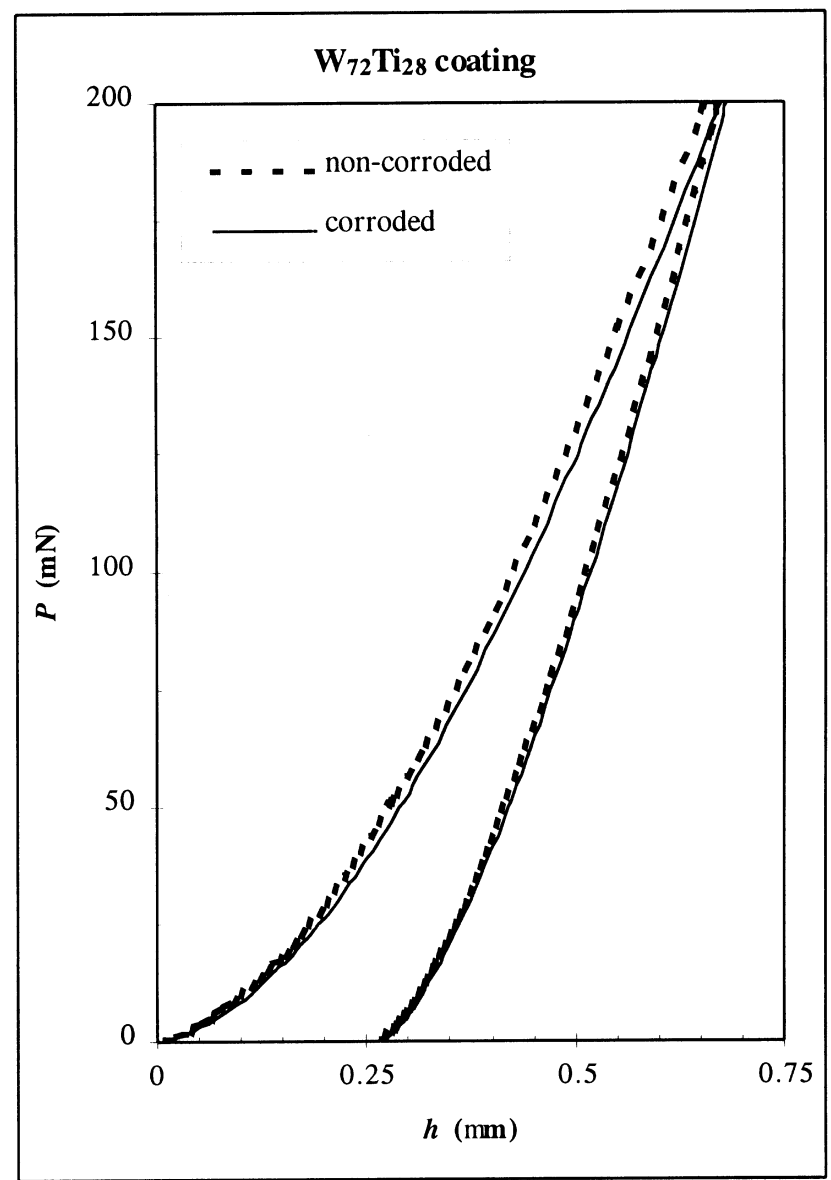

Fig. 3. Indentation load vs indentation depth curves for a W-Ti sputtered coating obtained before and after corrosion.

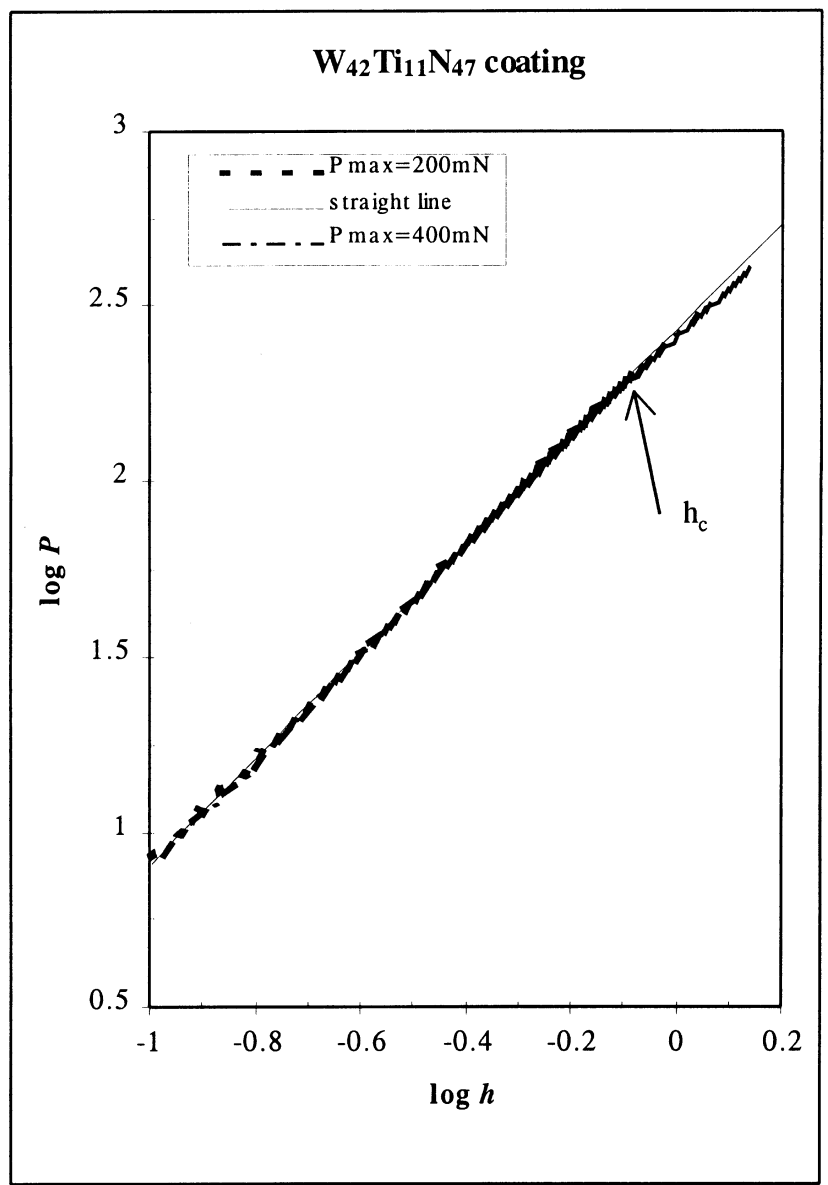

Fig. 4. Loading part of the indentation load vs indentation depth curves for a $\mathrm{W}-\mathrm{Ti}-\mathrm{N}$ sputtered coating obtained with a maximum load of 200 and $400 \mathrm{mN}$.

proposed by those authors [6]. After some simplifications, the equation that permits calculation of the hardness of the film $\left(H_{\mathrm{f}}\right)$ from the hardnesses of the composite $\left(H_{\mathrm{c}}\right)$ and the substrate $\left(H_{\mathrm{s}}\right)$, is :

$\frac{H_{\mathrm{c}}-H_{\mathrm{s}}}{H_{\mathrm{f}}-H_{\mathrm{s}}}=\frac{h_{\mathrm{pc}}}{h_{\mathrm{c}}}$

The critical depth value should be corrected $\left(h_{\mathrm{c}(\mathrm{pc})}\right)$ for the geometrical defects presented above and for the elastic contribution $\left(h_{\mathrm{e}}\right)$. This can be done by considering the following equations proposed by Fernandes et al. [6]:

$h_{\mathrm{c}(\mathrm{pc})}=a+b\left(h_{\mathrm{c}}-h_{\mathrm{e}}\right)$

$\frac{\mathrm{d} h_{\mathrm{e}}}{\mathrm{d} P}=\frac{1}{2} \sqrt{\frac{\pi}{24.5}}\left(\frac{1}{E_{\mathrm{r}}}\right)\left(\frac{1}{h_{\mathrm{pc}}}\right)$

where $a$ and $b$ are the correction constants presented in Eqn (1) and

$\left(1 / E_{\mathrm{r}}\right)=\left(1-v^{2}\right) / E+\left(1-v_{\mathrm{o}}^{2}\right) / E_{\mathrm{o}}$.

By combining these equations and considering that for a 
Vickers geometry the hardness is given by $H=P /\left(24.5 h^{2}\right)$, then

$h_{\mathrm{c}(\mathrm{pc})}=\frac{\frac{a}{b}+h_{\mathrm{c}}}{\frac{1}{b}+\frac{1}{2} \sqrt{24.5 \pi}\left(\frac{H_{\mathrm{f}}}{E_{\mathrm{r}}}\right)}$.

Table 4 summarises the results obtained for the Young's modulus and hardness for corroded and non-corroded films, determined for the 200 and $400 \mathrm{mN}$ loads, before and after correction by application of the hardness model described above.

Two main points should be noted from the analysis of Table 4. The first is the good agreement between the hardness values measured using low indentation loads and those obtained for high indentation loads using the model proposed by Fernandes et al. [6], which eliminates the substrate contribution. The second is the small difference in the values of $H$ and $E$ (in both cases lower than $20 \%$ ) obtained for the as-deposited and the corroded samples, which indicates that the degradation is really localised and only affects the material very close to the corrosion pits.

Regarding the oxidised samples, taking into account the smaller thickness of the as-deposited coating and the even thinner remaining non-degraded coating, initially only the $200 \mathrm{mN}$ load was used. Nevertheless, it was soon concluded that, for these samples and loads, the measured hardness values were also influenced by the substrate material. Thus, the model presented was applied and a lower indentation load of $100 \mathrm{mN}$ was used. The results are presented in Table 5. As for corroded samples, good agreement can be found between the results determined on the as-deposited and on the non-degraded part of the oxidised coatings. There is very good agreement between the hardness model and experimental results in this case also.
Concerning the validity of the results obtained by the ultramicroindentation technique, some remarks can be made as follows :

- It seems that this technique is suitable for the determination of the elastic modulus of thin films. In fact, in spite of it being very difficult to compare the results obtained with those in the literature, since it is well known that sputtering techniques give rise to films with different properties from bulk materials, it is possible to establish some relations between the different values. Taking into account that the $E$ values for bulk Ti and $\mathrm{W}$ are 115 and $410 \mathrm{GPa}$ [12], respectively, the calculated values for $\mathrm{W}-\mathrm{Ti}$ films are reasonable, see Table 4. In fact, for these films the values are between those of bulk W and Ti, the highest value (closer to the bulk $\mathrm{W}$ value) corresponding to the film with lower content in Ti. For the films containing nitrogen, the agreement is not so good. First, in spite of the fact that the films were obtained from the same target $(\mathrm{W}+10$ wt. \% Ti) the $E$ values are a little different (e.g. 341 and $382 \mathrm{GPa}$, see Tables 4 and 5). This could be attributed to either the small differences in the chemical composition of the films or to the use of lower indentation loads in the case of the film with the highest hardness value [6]. Secondly, these values are lower than those found for $\mathrm{TiN}-590 \mathrm{GPa}$ - (it was not possible to find a value of $E$ for $\mathrm{WN}$ in the literature), although it is known that in some cases the $E$ values determined in the coatings are lower than those of the bulk materials $[13,14]$.

- The small differences in the hardness values should be related to several factors such as: the incomplete removal of the oxide layers $\left(\mathrm{W}_{43} \mathrm{Ti}_{13} \mathrm{~N}_{44}\right.$ samples before and after oxidation, see Table 5), the use of different indentation loads and/or chemical composition (compare as-deposited $\mathrm{W}_{42} \mathrm{Ti}_{11} \mathrm{~N}_{47}$ and $\mathrm{W}_{43} \mathrm{Ti}_{13} \mathrm{~N}_{44}$ samples) and the difficulty in determining the inflection point,

Table 4

Hardness and Young's modulus values for $\mathrm{W}-\mathrm{Ti}-(\mathrm{N})$ coatings before and after corrosion

\begin{tabular}{|c|c|c|c|c|c|}
\hline & & $P(\mathrm{mN})$ & $E(\mathrm{GPa})$ & $\begin{array}{l}\text { Before hardness model } \\
H(\mathrm{GPa})\end{array}$ & $\begin{array}{l}\text { After hardness model } \\
H(\mathrm{GPa})\end{array}$ \\
\hline \multirow[t]{4}{*}{$\mathrm{W}_{42} \mathrm{Ti}_{11} \mathrm{~N}_{47}$} & Non-corroded & 200 & 341 & 35.5 & - \\
\hline & & 400 & 293 & 26.3 & 35.5 \\
\hline & Corroded & 200 & 320 & 37.3 & - \\
\hline & & 400 & 252 & 26.3 & 36.3 \\
\hline \multirow[t]{4}{*}{$\mathrm{W}_{72} \mathrm{Ti}_{28}$} & Non-corroded & 200 & 203 & 24.8 & - \\
\hline & & 400 & 148 & 17.2 & 21.1 \\
\hline & Corroded & 200 & 242 & 23.2 & - \\
\hline & & 400 & 188 & 18.8 & 20.9 \\
\hline
\end{tabular}


Hardness and Young's modulus values for $\mathrm{W}-\mathrm{Ti}-(\mathrm{N})$ coatings before and after oxidation

\begin{tabular}{|c|c|c|c|c|c|}
\hline & & $P(\mathrm{mN})$ & $E(\mathrm{GPa})$ & $\begin{array}{l}\text { Before hardness model } \\
H(\mathrm{GPa})\end{array}$ & $\begin{array}{l}\text { After hardness model } \\
H(\mathrm{GPa})\end{array}$ \\
\hline \multirow[t]{4}{*}{$\mathrm{W}_{93} \mathrm{Ti}_{7}$} & Non-oxidised & 100 & 354 & 20.4 & 24.7 \\
\hline & & 200 & 271 & 12.1 & 21.2 \\
\hline & Oxidised & 100 & 343 & 18.3 & - \\
\hline & & 200 & 304 & 14.6 & 20.0 \\
\hline \multirow[t]{4}{*}{$\mathrm{W}_{43} \mathrm{Ti}_{13} \mathrm{~N}_{44}$} & Non-oxidised & 100 & 384 & 33.1 & 35.0 \\
\hline & & 200 & 327 & 26.3 & 40.6 \\
\hline & Oxidised & 100 & 382 & 37.9 & 39.3 \\
\hline & & 200 & 314 & 24.2 & 40.7 \\
\hline
\end{tabular}

corresponding to the beginning of the substrate influence, in the loading curve $\left(\mathrm{W}_{72} \mathrm{Ti}_{28}\right.$ coating for 200 and $400 \mathrm{mN}$ indentation loads-Table 4).

\section{Conclusions}

This study leads to the following conclusions :

- $\mathrm{W}-\mathrm{Ti}-\mathrm{N}$ films were deposited by sputtering on steel substrates.

- Detailed characterisation of the corrosion and oxidation behaviours was performed.

- Corrosion takes place locally by pitting whereas oxidation gives rise to uniform degradation over all the surface of the samples.

- The ultramicroindentation apparatus was calibrated for hardness and Young's modulus measurements.

- $H$ and $E$ values for the as-deposited and non-degraded parts of corroded and oxidised samples are very similar.

-After application of a model to eliminate the substrate contribution when high indentation loads are used, the calculated $H$ values are close to those measured with low indentation loads.

-Ultramicroindentation is thus seen to be a powerful technique to estimate the state of mechanical degradation of a coated sample.

\section{Acknowledgements}

The authors are indebted to JNICT for financial support through project PBICT/C/CTM/1383/92.

\section{References}

[1] Doerner, M. F. and Nix, W. D., J. Mater. Res., 1986, 1, 601.

[2] Pharr, G. M., Oliver, W. C. and Brotzen, F. R., J. Mater. Res.,1992, 7, 613.

[3] Oliver, W. C. and Pharr, G. M., J. Mater. Res., 1992, 7, 1564.

[4] Trindade, A. C., Cavaleiro, A. and Fernandes, J.V., J. Test. Eval., 1994, 22, 365.

[5] Hendrix, B. C., J. Mater. Res. 1995, 10, 255.

[6] Fernandes, J. V., Trindade, A. C. and Menezes, L. F., submitted to J. Mater. Res.

[7] Louro, C. and Cavaleiro, A., Surf. Coat. Technol., 1995, 74/75, 998.

[8] Louro, C. and Cavaleiro, A., J.Electrochem. Soc., 1997, 144, 259.

[9] Brett, C. M. A. and Cavaleiro, A., Mat. Sci. Forum, 1995, 192(4), 797.

[10] Brett, C. M. A. and Nimigean, C. -M., Thin Solid Films, 1997, 311, 1.

[11] Brett, C. M. A. and Cavaleiro, A., Thin Solid Films, 1998, 322, 263

[12] Waterman, N. A. and Ashby, M. F., eds., Elsevier Materials Selector, Vol. 2, Elsevier Applied Science, Essex, U.K., 1991.

[13] Holleck, H., J. Vac. Sci. Technol. A., 1986, 4, 2661.

[14] Rosenmayer, C. T., Brotzen, F. R. and Gale, R. J., in Thin Films: Stresses and Mechanical Properties, Vol. 130, ed. J. C. Bravman et al. MRS Series, Pennsylvania, 1989, p. 77. 